\title{
BMJ Open Tackle-related injury rates and nature of injuries in South African Youth Week tournament rugby union players (under-13 to under-18): an observational cohort study
}

\author{
Nicholas Burger, ${ }^{1}$ Mike I Lambert, ${ }^{1}$ Wayne Viljoen, ${ }^{2}$ James C Brown, ${ }^{1,3}$ \\ Clint Readhead, ${ }^{2}$ Sharief Hendricks ${ }^{1}$
}

To cite: Burger N, Lambert MI, Viljoen W, et al. Tackle-related injury rates and nature of injuries in South African Youth Week tournament rugby union players (under-13 to under18): an observational cohort study. BMJ Open 2014;4: e005556. doi:10.1136/ bmjopen-2014-005556

- Prepublication history for this paper is available online. To view these files please visit the journal online (http://dx.doi.org/10.1136/ bmjopen-2014-005556).

Received 26 April 2014 Revised 15 July 2014 Accepted 24 July 2014

CrossMark

For numbered affiliations see end of article.

Correspondence to Nicholas Burger; nicholas.burger@uct.ac.za

\section{ABSTRACT}

Objectives: The tackle situation is most often associated with the high injury rates in rugby union. Tackle injury epidemiology in rugby union has previously been focused on senior cohorts but less is known about younger cohorts. The aim of this study was to report on the nature and rates of tackle-related injuries in South African youth rugby union players representing their provinces at national tournaments.

Design: Observational cohort study.

Setting: Four South African Youth Week tournaments (under-13 Craven Week, under-16 Grant Khomo Week, under-18 Academy Week, under-18 Craven Week).

Participants: Injury data were collected from 3652 youth rugby union players (population at risk) in 2011 and 2012.

Outcome measures: Tackle-related injury severity ('time-loss' and 'medical attention'), type and location, injury rate per $1000 \mathrm{~h}$ (including $95 \% \mathrm{Cls}$ ). Injury rate ratios (IRR) were calculated and modelled using a Poisson regression. A $\chi^{2}$ analysis was used to detect linear trends between injuries and increasing match quarters.

Results: The 2012 under-13 Craven Week had a significantly greater 'time-loss' injury rate when compared with the 2012 under-18 Academy Week (IRR=4.43; $95 \% \mathrm{Cl} 2.13$ to $9.21, \mathrm{p}<0.05$ ) and under-18 Craven Week (IRR=3.52; $95 \% \mathrm{Cl} 1.54$ to $8.00, \mathrm{p}<0.05$ ). The Poisson regression also revealed a higher probability of 'overall' ('time-loss' and 'medical attention' combined) and 'time-loss' tackle-related injuries occurring at the under- 13 Craven Week. The proportion of 'overall' and 'time-loss' injuries increased significantly with each quarter of the match when all four tournaments were combined $(p<0.05)$.

Conclusions: There was a difference in the tacklerelated injury rate between the under-13 tournament and the two under-18 tournaments, and the tackle-related injury rate was higher in the final quarter of matches. Ongoing injury surveillance is required to better interpret these findings. Injury prevention strategies targeting the tackle may only be effective once the rate and nature of injuries have been accurately determined.

\section{Strengths and limitations of this study}

- This study is novel as it reports specifically on tackle-related injury rates and the nature of injury in high-level South African youth rugby union players.

- The findings may help identify tackle injury prevention strategies for other youth rugby union players.

- The findings may also help prepare medical professionals for injury assessment and management at youth rugby union tournaments.

- Only injuries reported to the tournament doctor were included in the analysis.

- Data regarding height and weight for injured and uninjured players were not gathered; therefore, player mismatch could not be analysed as a potential injury risk factor.

- The findings in this study should be generalised with caution as the analysis involved a specific cohort of players at a week-long tournament in which the match load was high compared to the recovery period.

\section{INTRODUCTION}

Rugby union is a team sport played worldwide and characterised by frequent contact and collision situations between players. ${ }^{1-3}$ The ability to tolerate and contest these situations is a prerequisite for participation and success in the sport. ${ }^{2} 45$ The high frequency of collisions places rugby players at a higher risk of injury when compared with other non-collision team sports such as soccer and cricket. ${ }^{6} 7$ In particular, the tackle is the contact event most often associated with this high rate of injury. ${ }^{8-10}$

The tackle is defined as "any event where one or more tacklers (player or players making the tackle) attempt to stop or impede the ball-carrier (player carrying the 
ball) whether or not the ball-carrier was brought to ground." ${ }^{10}$ The tackle is an effective way to try and regain possession of the ball, and to prevent the attacking team from gaining field territory and advancing into a point-scoring position. ${ }^{5}$

Tackle-related injury rates have previously been reported for both league (professional English Premiership ${ }^{8}$ and community level rugby ${ }^{11}$ ) and tournament (Rugby World $\mathrm{Cup}^{12}$ ) formats. The tackle is responsible for a high proportion of upper body injuries in tacklers, particularly concussion, head/neck and shoulder injuries, and ball-carriers are more likely to sustain injuries to the lower body, particularly thigh muscle and knee injuries. ${ }^{89} 13$

Despite the plethora of tackle injury studies with a focus on senior rugby union players, ${ }^{9} 1014$ less is known about youth cohorts. Therefore, the aim of this study was to report on the nature and rates of tackle-related injuries occurring at four national youth rugby union tournaments which were hosted by the South African Rugby Union (SARU) in 2011 and 2012. It is noteworthy that this study is unique in comparison to previous research as these tournaments spanned only 1 week and have a high match load compared to the recovery period.

The specific questions of this study, pertaining to tackle-related injuries at youth rugby union tournaments, are as follows: (1) what is the injury rate in tournaments, (2) do injury rates differ across tournaments, (3) what are the injury type proportions at tournaments, (4) do injuries occur at different anatomical locations for ball-carriers and tacklers and (5) does the rate of injury events increase with match time? The answers to these questions may contribute to the development and implementation of targeted injury prevention and management strategies in youth rugby.

\section{METHODS}

SARU coordinates an injury-surveillance project, via the BokSmart National Rugby Safety Programme, ${ }^{15}$ whereby information about all injuries that occur at their Youth Week tournaments are recorded and transcribed in an injury database. Authors were granted access to this database for analysis by SARU and the UCT Human Research Ethics Committee (HREC Ref: 438/2011). All players attending the Youth Week tournaments and their parents/legal guardians signed the SARU Medical and Anti-Doping informed consent form which has a section dedicated to explaining the details of the injurysurveillance project. No player was allowed to participate in the SARU Youth Week tournaments if this form was not completed and signed by the player and his parent/ legal guardian and submitted to the team manager. Assent was given by the player at the time of the injury to analyse the recorded information. The Youth Week tournaments are a showcase for South Africa's most talented schoolboy players and include the under-13 Craven Week, under-16 Grant Khomo Week, under-18 Academy Week and under-18 Craven Week tournaments. These tournaments are unique in that they only span the course of 1 week and may place increased physical demands on players. Participating teams are formed through the selection of the top schoolboy players from within each of the country's 14 provincial rugby unions in addition to one Namibian and one Zimbabwean team. In the case of the two under-18 tournaments, Craven Week involves the best schoolboy players from each union, while the Academy Week involves the second tier of players from each union. Each team included 22 players with each player required to start and complete at least one match at the tournament unless forced off the field of play due to injury.

The structure of each week varied across different tournaments (table 1). 'Match days' (Ms) are defined as days on which all teams played an official tournament match on the same day. For the under-18 Craven Week, when only half the teams played in an alternating fashion for the first 4 days, one $M$ would span 2 days to include all the team matches. These days were termed 'tournament Ms' (TM), that is, any day on which official rugby matches were played. This was conducted for the purpose of comparing the daily load on the tournament medical staff. These terms should be contrasted to 'rest days' (Rs), on which teams were able to partake in other sporting or recreational activities. Exposure was only calculated using Ms (not Rs).

A SARU-appointed doctor was on duty at each tournament to assess every injury that occurred. Details about each injury were recorded on an injury collection form

Table 1 Tournament details of the four South African Rugby Union (SARU) Youth Week tournaments, 2011 vs 2012

\begin{tabular}{|c|c|c|c|c|c|c|c|c|}
\hline \multirow[b]{2}{*}{ Year } & \multicolumn{2}{|c|}{$\begin{array}{l}\text { Under-13 } \\
\text { Craven Week }\end{array}$} & \multicolumn{2}{|c|}{$\begin{array}{l}\text { Under-16 } \\
\text { Grant Khomo } \\
\text { Week }\end{array}$} & \multicolumn{2}{|c|}{$\begin{array}{l}\text { Under-18 } \\
\text { Academy Week }\end{array}$} & \multicolumn{2}{|c|}{$\begin{array}{l}\text { Under-18 Craven } \\
\text { Week }\end{array}$} \\
\hline & 2011 & 2012 & 2011 & 2012 & 2011 & 2012 & 2011 & 2012 \\
\hline Teams & 18 & 18 & 18 & 20 & 26 & 26 & 20 & 20 \\
\hline Matches & 36 & 36 & 27 & 30 & 39 & 39 & 30 & 29 \\
\hline Match time (min) & 40 & 40 & 60 & 60 & 70 & 70 & 70 & 70 \\
\hline Tournament structure & \multicolumn{2}{|c|}{$\mathrm{M}, \mathrm{M}, \mathrm{R}, \mathrm{M}, \mathrm{M}$} & \multicolumn{2}{|c|}{$\mathrm{M}, \mathrm{M}, \mathrm{R}, \mathrm{M}$} & \multicolumn{2}{|c|}{$\mathrm{M}, \mathrm{M}, \mathrm{R}, \mathrm{M}$} & \multicolumn{2}{|c|}{ TM, TM, TM, TM, R, M } \\
\hline Exposure time (h) & 720 & 720 & 810 & 900 & 1365 & 1365 & 1050 & 1015 \\
\hline
\end{tabular}


that was designed based on the Consensus Statement for injury surveillance. ${ }^{16}$ Only data pertaining to the tackle event were analysed for the purposes of this study.

The injury definition for these tournaments, adapted from the Rugby Union injury Consensus Statement, ${ }^{16}$ was stated as "any physical complaint, which was caused by a transfer of energy that exceeded the body's ability to maintain its structural and/or functional integrity, that was sustained by a player during a rugby match and required attention from the SARU tournament doctor."

'Time-loss' and 'medical attention' tackle-related injuries were reported for this study. A 'time-loss' injury was an injury (based on the aforementioned definition) that resulted in the player being absent for more than one match in a tournament, or more than one day of normal/planned recreational activities during or after the tournament. Injuries were confirmed as 'time-loss' injuries during the course of the tournament or via telephonic follow-up after the tournament. Weekly phone calls were made to assess the state of the injury until the player returned to practice. 'Medical attention' injuries required treatment from the tournament doctor, but resulted in no loss in recreational play or practice time. 'Overall' injuries included 'medical attention' and 'timeloss' injury events. Owing to the short duration of each tournament and low absolute injury numbers, 'medical attention' injuries were included during the analyses in addition to 'time-loss' injury data to gain insight into the rate and nature of tackle-related injuries.

The 'type' of injury was categorised as concussion, spinal cord, broken bone/fracture, joint/ligament/ tendon, muscle, bruise, laceration (including skin abrasion) or other by the tournament doctor. If the tournament doctor was unable to diagnose the injury at the time, the injury 'type' was recorded as 'unsure'. The 'location' of the injury was categorised into an anatomical group: head/neck, upper torso, upper limb, lower torso, lower limb or 'unsure'.

\section{Statistical analysis}

Player exposure time was calculated for all 2011 and 2012 tournaments based on the current injury collection consensus statement for rugby ${ }^{16}$;

$$
\text { Exposure time }=\mathrm{N}_{\mathrm{M}} \times \mathrm{P}_{\mathrm{M}} \times \mathrm{D}_{\mathrm{M}} \text {. }
$$

For this calculation, $\mathrm{N}_{M}$ is the number of matches, $\mathrm{P}_{\mathrm{M}}$ the number of players per match (ie, 30 players from both sides) and $\mathrm{D}_{\mathrm{M}}$ the duration of the match in hours. This exposure time was used to determine the injury rate and corresponding 95\% CIs for the number of tackle-related injuries per $1000 \mathrm{~h}$ of match play regardless of whether a player was injured more than once. ${ }^{17}$

The injury rate ratios (IRR) and corresponding 95\% CIs were calculated ${ }^{18}$ to determine the difference in injury rates at different tournaments (each year was analysed separately). The two under-18 tournaments were analysed separately because they are two different levels of play, that is, tier-one (under-18 Craven Week) and tier-two (Academy Week), they have different tournament structures, and therefore have different exposure times (table 1). The IRR was calculated by dividing the injury rate of one tournament, for example, tournament 'A' (numerator-may be representative of any tournament from either year), by its total player exposure time, and then dividing this by the equivalent value for the specific tournament to which it was compared, for example, tournament ' $\mathrm{B}$ ' (denominator-must be representative of another tournament from the same year);

$$
\mathrm{IRR}=\frac{\text { injury rate }_{\mathrm{A}} / \text { exposure }_{\mathrm{A}}}{\text { injury rate }_{\mathrm{B}} / \text { exposure }_{\mathrm{B}}} .
$$

The SE of the log of the IRR was calculated by dividing by dividing 1 by the total the total number of tackle injuries of each of the two compared tournaments $(y)$, and finding the square root of their sum;

$$
\mathrm{SE} \log \mathrm{IRR}=\sqrt{\frac{1}{\mathrm{y}_{\mathrm{A}}}+\frac{1}{\mathrm{y}_{\mathrm{B}}}} .
$$

CIs $(95 \%)$ were then calculated by using the log of the IRR and the SE of the log;

$$
95 \% \mathrm{CI}=\log \mathrm{IRR} \pm 1.96 \times \mathrm{SE} \log \mathrm{IRR} .
$$

The IRR was considered to be significantly greater for the numerator if both $95 \%$ CIs were greater than 1.0. Conversely, it was considered to be significantly lower for the numerator if both $95 \%$ CIs were less than 1.0.

Significant findings from the IRR analysis were verified using VRP injury statistics software (University of North Carolina, Injury Prevention Research Center). ${ }^{19}$ The IRR between any two tournaments was only considered to be significant if the VRP analysis yielded a $p$ value of less than 0.05 .

A Poisson regression was modelled using STATA V.11.1 (StataCorp LP, USA) to determine the probability of injury at the tournaments (both years were combined and the under-18 Craven Week tournament was used as the reference, ie, denominator).

A $\chi^{2}$ analysis was conducted using GraphPad Prism 5 (V.5.02 for Windows) to determine whether there were any significant linear trends $(\mathrm{p}<0.05)$ between the proportion of tackle-related injuries occurring in each match quarter for all tournaments across both years.

\section{RESULTS}

Injury surveillance was conducted on 1804 players in 2011 and on 1848 players in 2012 (table 1). Sixty per cent of 'overall' injuries from 2011 and 2012 (n=260 of 436 injuries) were tackle-related injuries. Sixty-one per cent of 'overall' tackle-related injuries ( $n=158$ of 260 injuries) were to the tackler and $39 \% \quad(n=102$ of 260 injuries) were to the ball-carrier. Sixty-one per cent of all 'time-loss' injuries from 2011 and 2012 (n=104 of 171 
injuries) were associated with the tackle. Fifty-five per cent of tackle-related 'time-loss' injuries ( $\mathrm{n}=57$ of 104 injuries) were to the tackler and $45 \%$ ( $n=47$ of 104 injuries) were to the ball-carrier. Injury rates were calculated for each tournament in both years (table 2).

The Poisson regression model revealed no significant differences in 'overall' and 'time-loss' tackle-related injury rates at different tournaments when both years were combined. However, there was a higher probability of 'overall' tackle-related injury at the under-13 Craven Week when compared with the under-18 Craven Week (IRR=1.38; 95\% CI 0.96 to $1.99, \mathrm{p}=0.08)$. Tackle-related 'time-loss' injury also had a higher probability of occurring at the under-13 Craven Week when compared with the under-18 Craven Week (IRR=1.79; 95\% CI 0.99 to $3.23, \mathrm{p}=0.05$ ).

There were no significant differences when 'overall' and 'time-loss' tackle-related IRRs were calculated for the 2011 tournaments. However, there was a significantly greater tackle-related 'time-loss' injury rate at the 2012 under-13 Craven Week tournament when compared with the 2012 under-18 Academy Week (IRR=4.43; 95\% CI 2.13 to $9.21, \mathrm{p}<0.05)$ and under-18 Craven Week (IRR=3.52; 95\% CI 1.54 to $8.00, \mathrm{p}<0.05)$. This is consistent with the result from the Poisson regression (see above; figure 1A, B).

The largest proportion of 'overall' tackle-related injuries were joint/ligament/tendon 'type' injuries (29\%; $\mathrm{n}=76$ of 260 injuries), bruise/contusions (22\%), muscle injuries $(15 \%)$, concussions $(10 \%)$ and lacerations (10\%) when all tournaments in 2011 and 2012 were combined. The greatest proportion of tackle-related 'time-loss' injuries were joint/ligament/tendon injuries (34\%; $\mathrm{n}=35$ of 104 injuries), concussions (25\%), broken bone/fractures (13\%) and muscle injuries (12\%).

When observing anatomical injury locations, $40 \%$ of 'overall' tackle-related injuries ( $\mathrm{n}=63$ of 158 injuries) to the tackler across all four tournaments in both years were head/neck injuries. Upper torso injuries (24\%) were the next most frequent in tacklers followed by lower limb (17\%) and upper limb (16\%) injuries. The majority of tackle-related 'time-loss' injuries to tacklers across all four tournaments in both years were head/ neck (44\%; n=25 of 57 injuries) followed by upper torso $(30 \%)$, lower limb (18\%) and upper limb (9\%) injuries.

In contrast, the majority of ball-carrier 'overall' tackle-related injuries were lower limb $(44 \%$; $=45$ of 102 injuries) followed by head/neck (25\%) and upper torso (22\%) injuries. The highest proportion of tackle-related 'time-loss' injuries to ball-carriers were lower limb (40\%; n=19 of 47 injuries) followed by upper torso $(28 \%)$ and head/neck (23\%) injuries.

When the 2011 and 2012 'overall' tackle-related injuries were combined, the proportion of injuries increased significantly with each quarter of the match $\left(\chi^{2}\right.$ linear trend: $\mathrm{p}<0.05)$. Approximately $35 \% \quad(\mathrm{n}=91$ of 260 injuries) of 'overall' tackle-related injuries across all tournaments in 2011 and 2012 occurred during the final

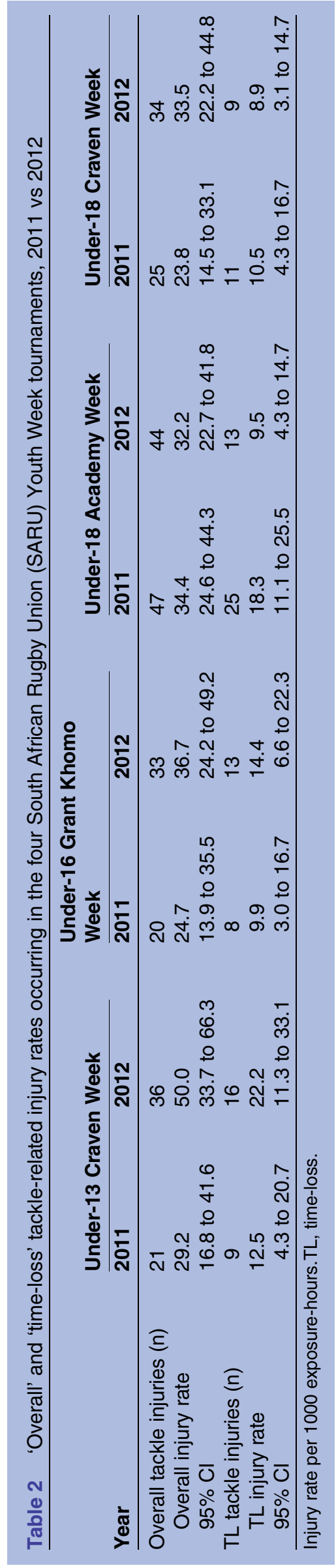



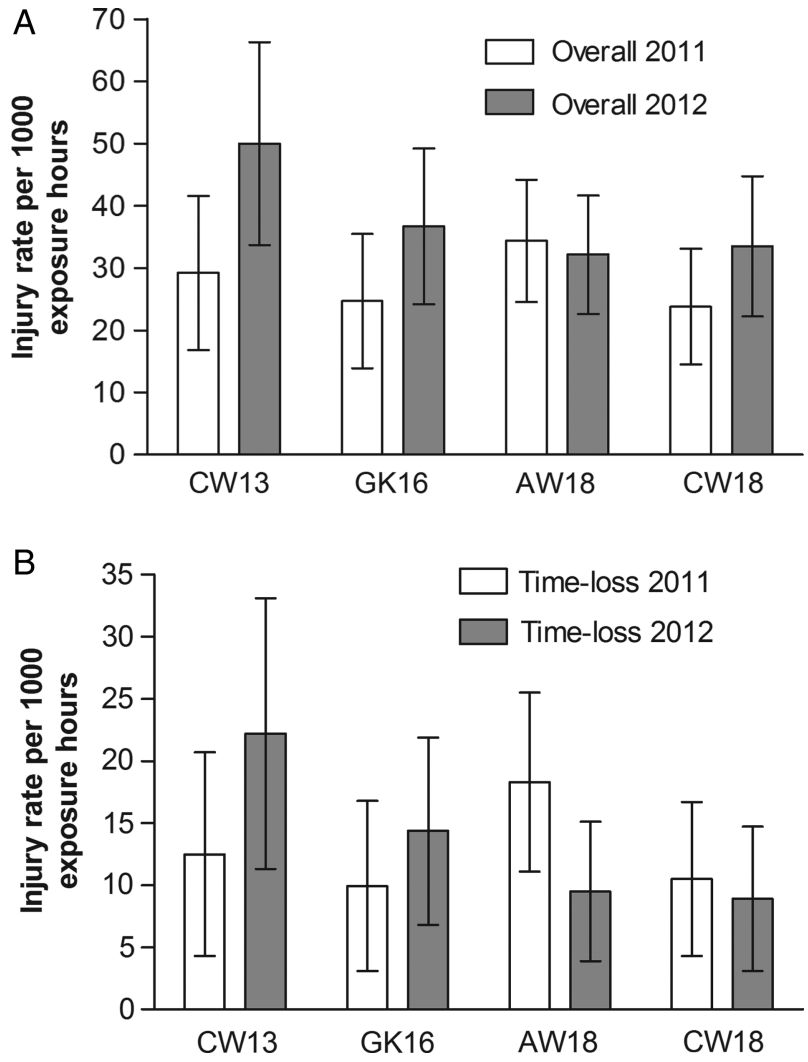

Figure 1 (A) A comparison of injury rates $( \pm 95 \% \mathrm{Cls})$ of 'overall' tackle-related injuries (including 'time-loss' injuries) at each South African Rugby Union (SARU) tournament in 2011 (white bars) and 2012 (shaded bars) and (B) a comparison of injury rates $( \pm 95 \% \mathrm{Cls})$ of tackle-related 'time-loss' injuries between each South African Rugby Union (SARU) tournament in 2011 (white bars) and 2012 (shaded bars). CW13, under-13 Craven Week; GK16, under-16 Grant Khomo Week; AW18, under-18 Academy Week; CW18, under-18 Craven Week).

quarter of the match. Twenty-four per cent of 'overall' tackle-related injuries occurred in the third quarter followed by the second (23\%) and first (17\%) quarters ( $1 \%$ were unknown). Significantly more tackle-related 'time-loss' injuries occurred in the final quarter of matches when both years were combined $(p<0.05)$. Thirty-seven per cent ( $\mathrm{n}=38$ of 104 injuries) of tackle-related 'time-loss' injuries across all tournaments in both years occurred during the final quarter of the match followed by the second, third and first quarters (all 20\%, 3\% were unknown).

\section{DISCUSSION}

This study is unique in that it reports exclusively on the nature and rates of tackle-related injuries in high-level South African youth rugby union players at a week-long tournament, and it will add to the current literature on tackle injury epidemiology, which is well documented in senior rugby union cohorts. ${ }^{9} 1014$
The high proportion of tackle-related injuries observed in this study is consistent with previous rugby union research. ${ }^{8-10}$ The higher proportion of 'overall' and 'time-loss' injuries occurring to the tackler during this study is consistent with some studies conducted in youth rugby union; ${ }^{20}{ }^{21}$ however, this finding is also in contrast to other studies which found ball-carriers to be at greater risk. ${ }^{13} 2223$ Therefore, based on these data, evidence is equivocal as to whether the tackler or ballcarrier is at greater risk during the tackle situation.

The rate of 'overall' tackle-related injuries at the Youth Week tournaments ranged from 23.8 injuries per 1000 exposure-hours (95\% CI 14.5 to 33.1) at the 2011 under-18 Craven Week tournament to 50.0 injuries per 1000 exposure-hours (95\% CI 33.7 to 66.3) at the 2012 under-13 Craven Week tournament (table 2). These injury rates are similar to those observed in English Premiership rugby union (33.9 injuries per 1000 exposure-hours (30.3 to 37.9$))^{8}$ and at the Rugby World Cup (tackling 20.2 injuries per 1000 exposure-hours (95\% CI 13.9 to 26.5$)^{12}$ and being tackled 18.7 injuries per 1000 exposure-hours (95\% CI 12.6 to 24.7)). However, they are much higher than those rates seen in English community-level rugby union (8.4 injuries per 1000 exposure-hours $(96 \%$ CI 7.8 to 9.0$)) .{ }^{11}$ This may be due to the higher intensity and level of competition associated with high-level youth and professional senior rugby union in comparison to subelite levels of play. It is noteworthy that the English community-level rugby study took place over three seasons in comparison to the compressed tournament structure observed at the SARU Youth Week tournaments and at the Rugby World Cup.

This study showed that there were significantly more 'time-loss' tackle-related injuries at the 2012 under-13 Craven Week in comparison to the two under-18 tournaments (Academy Week and Craven Week) in 2012. There were no significant differences in the probability of 'overall' and 'time-loss' tackle-related injuries between tournaments when both years were combined. However, there was a higher probability of an 'overall' and 'timeloss' tackle-related injury occurring at the under-13 Craven Week. Ongoing injury surveillance is necessary before these injury trends may be interpreted with confidence.

The type of tackle-related injuries did not differ greatly between tournaments. The majority of injuries to the tackler were to the head/neck region while ballcarriers most frequently suffered a lower limb injury. Similar results have been found in senior cohorts, ${ }^{14}$ although the current study's findings remain to be confirmed in other youth cohorts. These findings are not unexpected as the nature of the tackle situation in rugby union means that the upper extremity of the tackler and lower extremity of the ball-carrier are usually the first points of contact. ${ }^{24}$

The finding that the frequency of tackle-related injuries increased as playing time progressed within the match is consistent with previous findings in rugby 
union. ${ }^{1} 20$ This was significant for 'overall' and 'timeloss' tackle-related injuries and may be attributed to the effect of fatigue which has been found to play a role in reducing tackle technique proficiency in professional rugby league ${ }^{25}$ This may expose players to a greater risk of injury in the tackle situation as playing time in the match progresses. Therefore, each coach should make use of their entire squad and ensure that players are substituted and rotated in relation to their levels of fatigue. This is important at the Youth Week tournaments as matches are played on consecutive days and players have less time to recover. Coaches should also condition their players to tackle correctly under fatigued conditions. It is important to train, progress and reinforce tackle safety elements under fatigued and game-like conditions, where decision-making becomes important. By coaching and training these safety elements while fatigued, players will be more likely to execute a safer and more effective tackle under highly pressurised situations in dynamic environments.

Multiple risk factors play a role in causing an injury during a tackle event. For example, technique has been found to be an associated risk factor in previous tackle-related injury epidemiology research. ${ }^{14}{ }^{24}$ This may, in part, explain the higher rates of tackle-related injuries observed in the youngest playing group (the under-13 Craven Week). Older, more experienced players have been found to execute a greater proportion of effective tackles, and also miss fewer tackles and incur fewer tackle breaks. ${ }^{14}{ }^{26}$ It has also been found that players may only learn proper tackle technique at an older age. ${ }^{27}$

These findings emphasise the need for coaches to teach correct contact technique from an early age. ${ }^{27}$ Correct technique is not only necessary to prevent injury but also increases the likelihood of a successful performance outcome. ${ }^{5}$ Further research into which optimal movement patterns are required during tackle training is essential to help reduce injury rates. ${ }^{28}$

In addition to technique, it has also been suggested that the increased proportion of injuries associated with the tackle may be due to its open and unpredictable nature in comparison to more structured and controlled situations such as the scrum, maul or lineout. ${ }^{129}$ This may warrant research that involves explaining the role of complex, rapidly changing sport systems ${ }^{30}$ in tackle-related injury events. Using video analysis in future studies may be one method of achieving this.

The injury rates associated with the tackle may, however, be attenuated by adopting and implementing a multidisciplinary approach. ${ }^{21}$ The following points are examples that could be incorporated into an injury prevention plan: (1) education and coaching of safe and effective tackle techniques, for example, body height and position, head position and falling technique, ${ }^{20} 22{ }^{24}$ (2) prompting players to become aware of their immediate surroundings, ${ }^{29}$ (3) coaching tackle technique in a fatigued and non-fatigued state ${ }^{25}$ and (4) stricter officiating. ${ }^{102}$
Data from this study should be generalised with caution as the injury surveillance was conducted on a select cohort of high-level youth rugby players at specific week-long tournaments in South Africa. A comparison of injury rates between youth and senior cohorts, and tournament and league formats should also be made with caution. There are physical growth and developmental differences between age-group levels, and previous team sport injury epidemiological research has shown that injury rates at tournaments may be inflated in comparison to injury rates during a league season. ${ }^{31}$ This may be due to the higher intensity of play involved with a knock-out competition, fatigue-related factors due to matches being played on consecutive days or overreporting of injuries due to the presence of numerous medical personnel. Injury intervention strategies and injury management protocols should be sensitive to these differences. $^{2} 1422$

A limitation of this study is the short duration and competitive nature of the tournaments. This may result in teams 'hiding' injuries from the tournament doctor to keep that player available for the duration of the week. Players may also have been less likely to report injuries on the final day of the tournament as they might have preferred to see their own physician once they had returned home. ${ }^{7}$

Continued injury surveillance is required in youth rugby union cohorts so that patterns can be identified and better interpreted. A reduced injury risk and a subsequent decrease in injury rates in rugby union should hopefully result in an enhanced player experience, prolonged participation and increased player numbers.

\section{CONCLUSION}

This study provides insight into the nature and rates of tackle-related injuries occurring among youth rugby union players in South Africa. Tackle-related injury rate was highest at the 2012 under-13 Craven Week tournament, and there was a higher probability for a tackle-related injury to occur at the under-13 Craven Week when both years were combined. Ongoing injury surveillance is required to determine if this finding is repeated in future tournaments. Tackle-related injury type did not differ across tournaments for 'overall' and 'time-loss' injuries. Fatigue appears to play a role in the increasing tackle-related injury rates as match time progresses. Further research is required to determine the precise effect of fatigue on tackle technique proficiency and its relation to injury. This evidence, along with information detailing the precise risk factors and aetiology of tackle event injuries, may help guide the formation of effective injury prevention strategies.

Author affiliations

${ }^{1}$ Faculty of Health Sciences, UCT/MRC Research Unit for Exercise Science and Sports Medicine, Department of Human Biology, University of Cape Town, Cape Town, South Africa

${ }^{2}$ South African Rugby Union (SARU), Cape Town, South Africa 
${ }^{3}$ Department of Public and Occupational Health, EMGO Institute for Health and Care Research, VU University Medical Center, Amsterdam, The Netherlands

Acknowledgements The authors would like to thank the medical staff at all of these tournaments for their invaluable assistance with the injury data collection: all the nurses and paramedic staff at each of the tournaments as well as the tournament doctors: Dr Deon Van Tonder, Dr Malebo Mokotedi, Dr Andrea Burmeister, Dr Patho Cele, Dr Charles Smit, Dr Liz Leuenberger, Dr Ferdi Adams and Dr Viaan Vellerman. The authors would also like to thank SARU's BokSmart National Rugby Safety Programme and Medical Department for commissioning this injury surveillance project.

Contributors NB was granted access to analyse the data and was involved in conceptualising the manuscript; he also conducted statistical analyses and wrote the initial drafts of the manuscript. NB, JCB and SH collected and entered the data. All authors (MIL, WV, JCB, CR and SH) were involved in conceptualising and editing drafts of the paper, in the order that they appear on the author list.

Funding Funding was provided by the University of Cape Town (KW Johnston Scholarship)

Competing interests None.

Ethics approval UCT Human Ethics Committe.

Provenance and peer review Not commissioned; externally peer reviewed.

Data sharing statement Owing to the sensitive nature of the information and appropriate medical ethics, access to a more detailed aspect of the available data set will be reviewed on request and on a discretionary basis. Sharing of only depersonalised and non-relatable data will be considered, once permission has been received from WV or CR (who can be contacted via email through the corresponding author—nicholas.burger@uct.ac.za).

Open Access This is an Open Access article distributed in accordance with the Creative Commons Attribution Non Commercial (CC BY-NC 4.0) license, which permits others to distribute, remix, adapt, build upon this work noncommercially, and license their derivative works on different terms, provided the original work is properly cited and the use is non-commercial. See: http:// creativecommons.org/licenses/by-nc/4.0/

\section{REFERENCES}

1. Brooks JHM, Fuller CW, Kemp SPT, et al. Epidemiology of injuries in English professional rugby union: part 1 match injuries. $\mathrm{Br} J$ Sports Med 2005;39:757-66.

2. Brooks JHM, Kemp SPT. Recent trends in rugby union injuries. Clin J Sports Med 2008;27:51-73.

3. Haseler CM, Carmont MR, England M. The epidemiology of injuries in English youth community rugby union. Br J Sports Med 2010;44:1093-9.

4. Wheeler KW, Sayers MGL. Contact skills predicting tackle-breaks in rugby union. Int J Sports Sci Coach 2009;4:535-44.

5. Hendricks S, Lambert MI. Tackling in rugby: coaching strategies for effective technique and injury prevention. Int $J$ Sports Sci Coach 2010;5:117-35.
6. Fuller CW, Drawer S. The application of risk management in sport. Sports Med 2004;34:349-56.

7. Brown JC, Verhagen E, Viljoen W, et al. The incidence and severity of injuries at the 2011 South African Rugby Union (SARU) Youth Week tournaments. S Afr J Sports Med 2012;24:49-54.

8. Fuller CW, Brooks JHM, Cancea RJ, et al. Contact events in rugby union and their propensity to cause injury. Br J Sports Med 2007;41:862-7.

9. Quarrie KL, Hopkins WG. Tackle injuries in professional rugby union. Am J Sports Med 2008;36:1705-16.

10. Fuller CW, Ashton T, Brooks JHM, et al. Injury risks associated with tackling in rugby union. Br J Sports Med 2010;44:159-67.

11. Roberts SP, Trewartha G, England M, et al. Collapsed scrums and collision tackles: what is the injury risk? Br J Sports Med 2014; Published Online First:10 Feb 2014. doi:10.1136/bjsports-2013-092988

12. Best JP, Mclntosh AS, Savage TN. Rugby World Cup 2003 injury surveillance project. Br J Sports Med 2005;39:812-17.

13. Palmer-Green DS, Stokes KA, Fuller CW, et al. Match injuries in English youth academy and schools rugby union. Am J Sports Med 2013:41:749-55.

14. Mclntosh AS, Savage TN, McCrory P, et al. Tackle characteristics and injury in a cross section of rugby union football. Med Sci Sports Exerc 2010;42:977-84.

15. Viljoen W, Patricios J. BokSmart-implementing a National Rugby Safety Programme. Br J Sports Med 2012;46:692-3.

16. Fuller CW, Molloy MG, Bagate C. Consensus statement on injury definitions and data collection procedures for studies of injuries in rugby union. Br J Sports Med 2007;41:328-31.

17. Knowles SB, Marshall SW, Guskiewicz KM. Issues in estimating risks and rates in sports injury research. J Athl Train 2006;41:207-15.

18. Verhagen E, van Mechelen W. Sports injury research. Oxford: Oxford University Press, 2010.

19. VRP Injury Software. Injury Prevention Research Center. University of North Carolina. http://www.iprc.unc.edu/sportsinjurystatistics.shtml (accessed 10 Oct 2013).

20. Sparks JP. Rugby football injuries, 1980-1983. Br J Sports Med 1985;19:71-5.

21. Lee AJ, Garraway WM. Epidemiological comparison of injuries in school and senior club rugby. Br J Sports Med 1996;30:213-17.

22. Nathan M, Goedeke R, Noakes TD. The incidence and nature of rugby injuries experienced at one school during the 1982 rugby season. S Afr Med J 1983;64:132-7.

23. Nicol A, Pollock A, Kirkwood G, et al. Rugby union injuries in Scottish schools. J Public Health 2010;33:256-61.

24. Viljoen W, Treu P, Swart B. SA Rugby BokSmart: Safe and Effective Techniques in Rugby-Practical Guidelines. http://www.sarugby.co. za/boksmart/pdf/BokSmart\%20-\%20Safe\%20Rugby\%20Techniques \%20Practical\%20guidelines.pdf.2009 (accessed 23 May 2012).

25. Gabbett TJ. Influence of fatigue on tackling technique in rugby league players. J Strength Cond Res 2008;22:625-32.

26. Gabbett TJ. Physiological and anthropometric correlates of tackling ability in rugby league players. J Strength Cond Res 2009;23:540-8.

27. Hendricks S, Jordaan E, Lambert MI. Attitude and behaviour of junior rugby union players towards tackling during training and match play. Saf Sci 2012;50:266-84.

28. King D, Hume PA, Clark T. Nature of tackles that result in injury in professional rugby league. Res Sports Med 2012;20:86-104.

29. Garraway WM, Lee AJ, Macleod DAD, et al. Factors influencing tackle injuries in rugby union football. Br J Sports Med 1999;33:37-41.

30. Balague N, Torrents C, Hristovski R, et al. Overview of complex systems in sport. J Syst Sci Complexity 2013;26:4-13.

31. Emery CA. Injury prevention and future research. Med Sport Sci 2005;48:179-200. 